Legislation

\section{Should paediatricians support the European Paediatric Clinical Trials Register?}

\section{H M Sammons, C Naylor, I Choonara, C Pandolfini, M Bonati}

\section{Ensuring its success will help improve the use of medicines in children}

$\mathrm{T}$ he importance of clinical trials in children in providing a scientific evidence base for drug therapy is accepted by health professionals, regulatory authorities, the pharmaceutical industry, and the parents of children. Legislation in the USA alongside government investment in research has resulted in a significant increase in paediatric clinical trials in North America. ${ }^{1}$ European legislation is currently being proposed that will provide a financial incentive to the pharmaceutical industry to study medicines in Europe. The proposal has been prepared by the European Commission following extensive consultation. Within the UK the establishment of a Medicines for Children Research Network will hopefully also ensure that more clinical trials are performed in paediatric patients of all ages.

\section{REGISTRATION OF CLINICAL TRIALS}

There is increasing recognition that as well as performing clinical trials, registration is essential. ${ }^{2}{ }^{3}$ Many completed clinical trials are never published. A group of researchers in North America have studied the publication of clinical trials that had been presented as abstracts at the Society for Pediatric Research. They found that $28 \%$ of abstracts were subsequently not published. ${ }^{4}$ This however may have been an underestimate as they relied on the return of questionnaires from authors who had presented the abstracts. A British study of the publication rate following presentation at two national meetings found that $22 \%$ and $49 \%$ of the presentations were subsequently not published as full papers. ${ }^{5}$ In the majority of cases the authors did not submit their findings for publication.

The lack of publication of completed clinical trials adversely affects the evidence base on which decisions regarding choice of drugs and dosage in relation to efficacy and toxicity are made. In order to ensure that children receive the safest and most effective treatment, health professionals need the complete information. The existence of the European Paediatric Clinical Trials Register does not ensure publication. ${ }^{6}$ It does, however, alert health professionals to the fact that a clinical trial has been completed. This then allows researchers who are carrying out systematic reviews to contact the investigators directly and obtain unpublished data. The existence of a register also prevents duplication by investigators and encourages collaboration. Additionally, it allows sponsors (medical charities, Department of Health) to ensure that duplicate studies are not funded.

\section{Pharmaceutical industry}

Concern has been raised that clinical trials which produce negative results are deliberately suppressed by the pharmaceutical industry. ${ }^{78}$ In the UK, the Association of the British Pharmaceutical Industry (ABPI) has established a Clinical Trial Register. This register, however, is only voluntary and not all companies are supporting it. It is only public pressure or legislation that will ensure that the pharmaceutical industry fully supports the concept of registration of clinical trials.

\section{Compulsory registration}

Several leading adult medical journals have declared that clinical trials submitted for publication will need to have been registered in order for their findings to be published. ${ }^{9}{ }^{10}$ This is a welcome step and will ensure that clinical trials registers are used. The International Committee of Medical Journal Editors (ICMJE) has not advocated a particular register but has suggested that the register sponsored by the United States National Library of Medicine (www.clinicaltrials.gov) meets all their necessary requirements. ${ }^{9}$ Concerns have, however, been expressed in that this register is quite restrictive as to which trials can be registered ${ }^{10}$ (the register was primarily designed for
American trials which were being submitted to the Food and Drug Administration (FDA)).

An additional development in Europe is that all new clinical trials involving medicines need to be registered with the EMEA. This legislation affects both the pharmaceutical industry and academic investigators who carry out independent research. What is not known at this stage is how much of the information available on the European Clinical Trials Register will be accessible to academia, health professionals, and the public. A register that is only accessible to the regulatory authorities will not benefit children.

\section{DO PAEDIATRIC CLINICAL TRIALS NEED A SEPARATE REGISTER?}

Health professionals who work with children are well aware that many medicines used in paediatric patients are either unlicensed or used off label. ${ }^{11}$ It is well recognised that drug toxicity in children is different to that in adults. ${ }^{12}$ Additionally, the design of paediatric clinical trials is different to that in adults, where healthy volunteers can be used. ${ }^{13}$ Recruitment to paediatric clinical trials involves patients and therefore is usually slower, requiring more emphasis on safety than corresponding studies in adults. ${ }^{14}$ For these reasons, there is a clear need for a separate register of paediatric clinical trials.

\section{EUROPEAN PAEDIATRIC CLINICAL TRIALS REGISTER}

There is currently only one clinical trials register that exclusively deals with paediatric clinical trials. This register was established with funding from the European Community. ${ }^{6}$ The project commenced in January 2003 and currently involves four countries: Italy, France, Spain, and the UK. The lead centre is in Milan and the register went live on 1 July $2004 .{ }^{15}$ It can be accessed through the website www.dec-net.org.

The register is freely available to both health professionals and the public. Trial information is available in two different formats, a simple one aimed at parents and the public and a more advanced one aimed at health professionals. Users are, however, free to choose whether they obtain the simple or advanced information. Information listed in the register is as follows:

- Title of protocol

- Status of the clinical trial

- Disease

- Age and sex of patients being studied

- Aim of the study

- Contact details for lead investigator

- Participating centres/countries. 
The advanced view contains more details and includes administrative information about the trial (local protocol number, EUDRACT number, ISRCTN number). Also included are the following:

- Name of the drug

- Type of trial (therapeutic efficacy, pharmacokinetic, safety/toxicity)

- Inclusion criteria

- Exclusion criteria.

Since the official launch of the register, the website has seen an average of 400500 hits each month. As of January 2005 the website had had over 3700 visits. This illustrates the importance of ensuring that the website is user friendly.

The register currently contains details of over 60 clinical trials. These range from double blind randomised controlled trials to pilot studies and open observational studies. A wide range of clinical conditions are covered, several of which involve analgesia following surgery, the treatment of asthma, gastrooesophageal reflux, attention deficit hyperactivity disorder, HIV, and diabetes mellitus. The status of the vast majority of these trials is that they are currently recruiting patients and in only a few cases have the clinical trials been completed.
Within the UK there has been considerable support for the register from the Royal College of Paediatrics and Child Health, the Neonatal and Paediatric Pharmacists Group, and the ABPI. Over 40 of the clinical trials on the register are studies from the UK. More than 20 different academic units and NHS hospitals have already provided information on clinical trials that they are involved in. Ensuring the success of the only Paediatric Clinical Trials Register worldwide will help improve the use of medicines in children.

Arch Dis Child 2005;90:559-560.

doi: $10.1136 /$ adc. 2004.062836

\section{Authors' affiliations}

H M Sammons, C Naylor, I Choonara, Academic Division of Child Health, The Medical School, University of Nottingham, Derbyshire Children's Hospital, Derby, UK C Pandolfini, M Bonati, Mario Negri Institute, Milan, Italy

Correspondence to: Prof. I Choonara, Academic Division of Child Health, The Medical School, University of Nottingham, Derbyshire Children's Hospital, Uttoxeter Road, Derby DE22 3DT, UK; imti.choonara@nottingham. ac.uk

Competing interests: none declared

\section{REFERENCES}

1 Spielberg SP. Paediatric therapeutics in the USA and internationally: an unparalleled opportunity. Paed Perinat Drug Ther 2000;4:71-4.

2 Dickersin K, Rennie D. Registering clinical trials. JAMA 2003:290:516-22.

3 Steinbrook R. Public registration of clinical trials. N Engl J Med 2004;351:315-17.

4 Hartling L, Craig WR, Russell K, et al. Factors influencing the publication of randomized controlled trials in child health research. Arch Pediatr Adolesc Med 2004;158:983-7.

5 Riordan FAI. Do presenters to paediatric meetings get their work published? Arch Dis Child 2000;83:524-6

6 Pandolfini $\mathrm{C}$, Bonati $\mathrm{M}$, Sammons $\mathrm{H}$, et al. A European clinical trials registry for children. Paed Perinat Drug Ther 2003;5:98-100.

7 Herxheimer A, Mintzes B. Antidepressants and adverse effects in young patients: uncovering the evidence. CMAJ 2004; 170:487-9.

8 Whittington CJ, Kendall T, Fonagy $P$, et al. Selective serotonin reuptake inhibitors in childhood depression: systematic review of published versus unpublished data. Lancet 2004;363:1341-5.

9 De Angelis C, Drazen JM, Frizelle FA, et al. Clinical trial registration: a statement from the International Committee of Medical Journal Editors. N Engl J Med 2004;351:1250-1.

10 Abbasi K. Compulsory registration of clinical trials. BMJ 2004;329:637-8.

11 Turner S, Longworth A, Nunn AJ, et al. Unlicensed drug use on paediatric wards. BMJ 1998:316:343-5.

12 Choonara I, Rieder MJ. Drug toxicity and adverse drug reactions in children-a brief historical review. Paed Perinat Drug Ther 2002:5:12-18.

13 Keinonen T, Miettinen P, Saano V, et al. Clinical trials in children and healthy volunteers. Quality and characteristics of notifications reviewed by the regulatory agency in Finland. Paed Perinat Drug Ther 2003;5:175-82.

14 Peden V, Choonara I, Gennery B, et al. Recruiting children to a clinical trial. Paed Perinat Drug Ther 2000;4:75-8.

15 Bonati M, Pandolfini C, Rossi V, et al. Launch of a European paediatric clinical trials register. Paed Perinat Drug Ther 2004;6:38-9.

\section{Sikh birth customs}

\section{R Gatrad, J Jhutti-Johal, P S Gill, A Sheikh}

\section{An overview of Sikh theology and its impact on perinatal practice}

T his is the third in a series of occasional articles on birth customs among the major non-Christian faiths in the UK. Reviews on birth customs among Muslims and Hindus have already been published. ${ }^{1}{ }^{2}$ Here we provide an overview of the basic tenets of Sikh theology and its impact on perinatal practice.

\section{DEMOGRAPHY}

Although the largest Sikh communities are to be found in the Punjab in Northern India, Sikhs are now scattered around the globe, including Europe and North America. In the UK, where
Sikhism is the fourth commonest religion, there are over 336000 Sikhs. The largest Sikh conurbations are in Southall in west London and the West Midlands. ${ }^{3}$

\section{KEY BELIEFS}

The word "Sikh" is derived from a Sanskrit word "shisya" meaning a "learner" or a "disciple". Sikhism was founded by Guru Nanak in the 15th century against a backdrop of Hindu/ Muslim conflict. ${ }^{4}$ There then followed nine further gurus who promoted inclusiveness and union with God for all, irrespective of gender, caste, race, or religion. Guru Gobind Singh, the last guru, decreed that after his death Sikh scriptures in the form of the religious book called the Guru Granth Sahib, should be followed and command the same respect and authority as a human guru.

Sikhism is a monotheistic religion and the ultimate goal of Sikhs is to achieve liberation (Mukti or Moksha) from the cycle of birth, death, and rebirth and eventually be one with the Divine, depending on the outcome of their Karma (deeds).

Sikhs can essentially be divided into two main groups: the baptised and the non-baptised. The Pahul or baptism ceremony (Amrit Sanskar) is undertaken when an individual fully comprehends the implications of such an act. Hence, it is rare for a pre-pubescent child to be baptised. There is no upper age limit to baptism, which is encouraged for both men and women. The ceremony takes place in the presence of the Guru Granth Sahib. Here the principles of Sikh faith and other key instructions on how a baptised Sikh must live are imparted to 


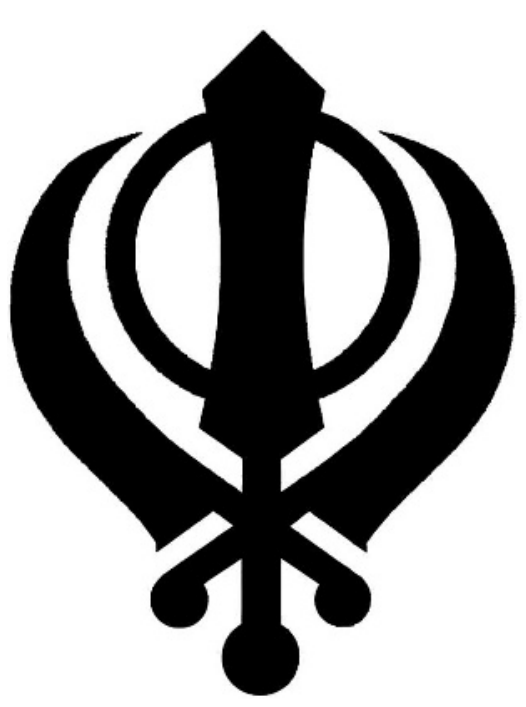

Figure 1 Khanda, the Sikh symbol, is made up of two swords, a symbol of fighting for what is right. Between them is a circle, depicting that God is one-without beginning or end.

the initiate. These include devotion to God; service to mankind; fighting against injustice; and defence of the weak. These religious virtues are represented by the religious Sikh symbol known as the Khanda (fig 1).

On acceptance of these instructions, five handfuls of Amrit (nectar of immortality-prepared by pouring water and sugar pellets into a steel bowl and stirring the mixture with a double edged dagger while selected verses from the Guru Granth Sahib are read out aloud) are drunk by the initiate and five handfuls are sprinkled over their hair and eyes. If a person does not have a Sikh name, they now take one. The person is thus formally admitted to the Khalsa (baptised) community. ${ }^{5}$ It now becomes obligatory for such a person to wear the outward symbols of Sikh

Box 1: External symbols worn by Sikhs - the "five Ks"

- Kes-uncut hair to preserve God-given human form

- Kangha-comb to keep hair tidy and symbolises discipline and clarity of mind

- Kirpan-a sword which symbolises freedom and justice

- Kara-iron/steel bracelet worn on right hand, reminding the wearer of God's strength and infinity

- Kachha-short breeches emphasising commitment to purity identity-the so-called "five $\mathrm{Ks}^{\prime \prime}$ (see box 1).

Baptised Sikhs (Amrit-dhari or Khalsa) constitute an "orthodoxy" within Sikhism. Non-baptised Sikhs (who form the majority in the UK) are either Kesdhari Sikhs (keep their hair unshorn and wear the outward symbols of the Sikh faith), or Mona Sikhs (retain an affiliation to the Khalsa but remove the outward symbols of the faith). This information can be useful for health professionals at various points of contact during antenatal and postnatal care (see below).

\section{PREGNANCY AND CHILDBIRTH}

Guru Nanak advocated a monogamous relationship that was not consanguineous. Every Sikh child is believed to contain a "divine spark" of the creator. For a Sikh, the point at which a baby is conceived represents the soul's entry into the world. Conception is therefore a sacred act, carried out within the confines of a marriage that has been blessed in front of the Guru Granth Sahib.

"In the mothers womb, life was enshrined and cherished. You were blessed with body and soul." (Guru Arjan, Guru Granth Sahib, p. 1004)

\section{Family planning}

This is left very much to the couple. There are no injunctions in Sikhism against the use of contraceptives within a married relationship and no insistence on abstinence.

\section{Sex determination}

Some Sikhs are now participating in the growing practice of gender selection, particularly in the hope of having a male child. Most South Asian cultures have traditionally valued a male child more than female because of the economic benefit and continuation of the family line. ${ }^{6}$ The gurus tried to reverse and halt this trend by giving women a special status as described in the Guru Granth Sahib. ${ }^{5}$ However, a strong desire to have a male child still continues today. From the religious viewpoint, the sex of a child is pre-ordained and any interference should therefore be discouraged.

\section{Diet, smoking, and alcohol}

All Sikhs, whether baptised or not are instructed to refrain from taking any form of intoxicant (smoking, drugs, alcohol, etc). However, in practice, although drinking alcohol is quite common among the non-baptised, particularly men, this is rare among women. Smoking is much less common and is still considered taboo by most Sikhs. Expectant mothers are encouraged during pregnancy to keep to a healthy diet to nourish the unborn child

A child is seen as a gift from God and therefore should be nurtured from conception. A baptised Sikh woman will refrain from eating meat and eggs, which may result in iron deficiency, requiring regular monitoring, with advice on alternative sources of iron.

\section{Abortion}

There is no specific dictate in religious texts about therapeutic abortions. Many Sikhs will therefore interpret certain parts of texts and make a personal decision when confronted with a clearly abnormal fetus. Generally, as Sikhs believe that the soul is "born" immediately on conception, abortion is not accepted. However, if the mother's life is threatened by the continuation of pregnancy then termination is often acceptable.

\section{Childbirth}

Sikhism does not prescribe any special rituals during labour. All family members will be encouraged to meditate and say prayers for the newborn and the mother. The mother herself will try and meditate during labour and also recall verses from the Guru Granth Sahib. As is the case with women in general, out of a sense of modesty, many Sikh mothers-to-be would prefer to be seen by female health professionals during pregnancy and labour. In the case of baptised Sikh women, the five Ks are worn at all times and the mother should be consulted before removing any of these items. A request for keeping the Kachha (underwear) on one leg may be made. Shaving of the perineum may not be acceptable to the patient and if it is clinically necessary a very sensitive approach is advised.

\section{Postnatal considerations}

After labour, the mother is encouraged to rest and recuperate. This is a cultural practice and not religious. Mothers should therefore be advised on early ambulation to prevent venous thrombosis. There is no concept of "pollution" (a state of being "unclean" as a result of vaginal discharge, precluding women from household chores) surrounding the mother either before, during, or after childbirth (in contrast to some other South Asian religions, such as Hinduism). ${ }^{7}$

A few days after birth the immediate family will go to the Gurdwara to present the baby to the Guru Granth Sahib and recite hymns that are expressive of joy and thankfulness. Karhah Prashad (sacred pudding) is also eaten. 


\section{Growth of Sikh babies}

A study by one of the authors, comparing preschool heights and weight of Europeans with five South Asian subgroups (Sikhs, Hindus, Muslim Pakistanis, Muslim Bangladeshis, and Muslim Gujaratis) in the West Midlands, showed that Sikh boys and girls were significantly heavier than the other South Asian subgroups at birth; this pattern continued until at least the age of 5 years. ${ }^{8}$ In addition, both Sikh males and females at birth were the tallest of all the Asian subgroups and were also taller than European babies; this pattern again continued up to at least the age of 5 years.

Growth is determined by genetic, nutritional, and other environmental factors. These variations could, it was speculated, be explained by the fact that Sikhs are the most affluent South Asian group in Walsall (West Midlands), resulting possibly in a more wholesome diet for the mother and baby.

Future research in this area could be directed, not only to repeating this relatively old study, but also to ascertain growth patterns beyond the age of 5 years.

\section{Naming customs}

Many Sikhs will name their baby on the fortieth day after birth in a simple child naming ceremony (Nam Karan). A prayer (Ardas) is recited. The Guru Granth Sahib is then opened at random and the first letter from the top of the left page is used as the first letter of the name of the child. Either the parents announce the name of the child immediately, or later after consulting other members of the family. Sikh parents may choose a name without this ceremony, and yet others will get the paternal aunt or another close relative to choose, a process which may result in delay in registering the infant's name.

Further, to emphasise the equality of human beings and in explicit rejection of the Hindu caste system, ${ }^{5}$ all men and women who joined the Khalsa add the name Singh (meaning "lion") to the forename of a son, and Kaur (meaning "princess") for girls. All Sikh names have a special religious meaning; for example, Baljit means "mighty victorious". It is of practical interest to note that these names are not gender specific; for example, as shown in table 1, Baljit Singh is a boy and Baljit Kaur is a girl. Some families use caste/surnames; for example, in the above case Baljit Khera instead of Baljit Singh. This could therefore lead to gender confusion and could possibly be avoided by the use of Singh or Kaur as the middle name, as many non-baptised Sikhs continue to use their caste/surname, particularly in
Table 1 Examples of Sikh names with their meanings

\begin{tabular}{ll}
\hline Name & Meaning \\
\hline Amariit & Forever victorious \\
Balraj & $\begin{array}{l}\text { Mighty king } \\
\text { Maljit }\end{array}$ \\
$\begin{array}{l}\text { Manhty victorious } \\
\text { Light of sages } \\
\text { Manjit }\end{array}$ & $\begin{array}{l}\text { The one who controls } \\
\text { the mind }\end{array}$ \\
Ranjit & Conqueror of the battle \\
Suchdev & God of peace \\
Sukhrai & King of peace \\
\hline
\end{tabular}

the UK. Thus Baljit Singh Khera would be a male.

\section{Breast feeding and weaning}

Breast feeding is positively encouraged within the Sikh faith as it is considered a completely natural process and the best nourishment for the infant. The duration of breast feeding and the timing of weaning the child is entirely a personal choice and not dictated by religious teaching.

There are however certain customs that may be carried out by some Sikh women which may have clinical ramifications. For example, a mother may return to her maternal home for 40 days after the birth of the baby, which may result in missing of postnatal appointments. However, these practices are rooted in culture and social tradition, often borrowed from other religions such as Hinduism, rather than Sikh theology, and can vary markedly from family to family.

We have encountered some other practices of individuals/families which have no sound theological basis in the Sikh religion, including:

- Belief in "hot" and "cold" foods. Certain foods are believed to have a "cooling" or "heating" effect on the function of various organs of the body. This concept is divorced from the actual temperature of food or even how spicy the food is. "Hot" foods such as lentils, aubergines, and eggs are thought to increase physical and emotional activity, and "cold" foods such as milk, white sugar, fruits, and cereals have a calming effect. This concept has particular relevance during pregnancy. For example, bleeding of pregnancy may be attributed to "hot" foods and therefore these are avoided; conversely the same foods are encouraged during the postpartum period and breast feeding.

- Role of Amrit-holy water. Some families insert a few drops of this especially prepared sweetened water into the mouth of the baby, while the mother, as a blessing and for its "cleansing" properties, also drinks some. Many Sikh babies are given a Kara (bangle), often on the thirteenth day, but there is no time constraint on when it is given, and the paternal or maternal immediate family may give it.

- Glass of water or something metallic under a baby's cot. Both of these customs are rooted in Indian tradition. Because of their upbringing in India, older Sikhs may follow these customs which may then be passed onto subsequent generations. Without such rituals, some families feel the baby is vulnerable from "evil" spirits.

- Home visits after birth. Some families in the UK are still superstitious and will not allow visitors to enter the house and directly visit the new baby and mother. They are often initially led to another room to "shake off" evil spirits.

- Fasting. This does not have any religious significance or merit within Sikh theology. Some women may fast during pregnancy for the wellbeing of their husbands as they are the providers of the family. This custom is "borrowed" from Hinduism. The possible risks of fasting to the unborn child should be highlighted to the expectant mother.

\section{Postmortem examinations and organ transplantation}

As with people from any cultural or religious background, this issue should be broached sensitively. There is no prohibition with respect to either postmortem examinations or organ transplants, as Sikhs fundamentally believe that the body is simply just a shell to transport the soul while it resides on its earthly sojourn. Death marks the release of the "knot" between body and soul.

When a child is miscarried, depending on the developmental stage of the embryo, no ceremony is usually conducted. The parents will be encouraged to pray and meditate for the soul. If a formed fetus dies in the womb and is delivered, then a ceremony may be conducted.

For a stillborn child or one who dies shortly after birth, most parents will want their baby to be cremated. This ceremony is usually for the immediate family only and culminates in the scattering of ashes into a river or sea. Sometimes this involves a trip to India where ashes of previous family members were disposed. This custom of scattering ashes in flowing rivers is practised as it precludes erection of 


\section{LEADING ARTICLE}

gravestones-a practice forbidden by the Sikh religion.

\section{CONCLUSIONS}

Since beliefs may vary among Sikhs, it is important to ask rather than assume what is important to the individual/ family. This is particularly so as there are generally no elaborate rituals or ceremonies, compared to other South Asian religions, surrounding childbirth within the Sikh faith.

Arch Dis Child 2005;90:560-563. doi: 10.1136/adc.2004.064378

\author{
................... \\ Authors' affiliations \\ R Gatrad, Manor Hospital, Walsall, UK \\ J Jhutti-Johal, Department of Theology, \\ University of Birmingham, UK \\ P S Gill, Department of Primary Care and \\ General Practice, University of Birmingham, \\ UK \\ A Sheikh, Division of Community Health \\ Sciences: GP Section, University of Edinburgh, \\ Edinburgh, UK \\ Correspondence to: Dr P S Gill, Department of \\ Primary Care and General Practice, University \\ of Birmingham, Birmingham B15 2TT, UK; \\ p.s.gill@bham.ac.uk \\ Competing interests: none declared
}

\section{REFERENCES}

1 Gatrad AR, Sheikh A. Muslim birth customs. Arch Dis Child Fetal Neonatal Ed 2001;84:F6-8.

2 Gatrad AR, Ray M, Sheikh A. Hindu birth customs. Arch Dis Child 2004;89:1094-7.

3 www.statistics.gov.uk/CCl/nugget.asp? $I D=293 \&$ Pos $=6 \&$ ColRank $=1 \&$ Rank $=3$ (accessed 27 June 2004).

4 Keay J. A history of India. London: HarperCollins, 2000.

5 www.allaboutsikhs.com (accessed 27 June 2004).

6 Jhutti J. Dowry among Sikhs in Britain. In: Menski W, ed. South Asian and the dowry problem. Stoke on Trent: Trentham Books, 1998.

7 Singh NGK. The feminine principle in the Sikh vision of the transcendent. Cambridge: Cambridge University Press, 1993.

8 Gatrad A, Birch N, Hughes M. Pre-school weights and heights of European and five sub-groups of Asians in Britain. Arch Dis Child 1994;71:207-10.

Working in paediatrics and not a member of the Royal College of Paediatrics and Child Health?
Have you thought about the benefits of joining?
Benefits and entitlements of membership
- Regular mailings including quarterly newsletter
- Listed in handbook plus your own copy at no extra charge
- Representation on Council (the College's governing body)
- Local support
- Archives of Disease in Childhood (BMJ cost to non members £206.00)
- Discount at Spring meeting
- Book club with discounts on books related to paediatrics
- CPD monitoring (fellows and associates)
- Voting at general meetings (fellows and ordinary members)
- Membership certificate (fellows and ordinary members)
- HST monitoring (ordinary members)
- Designation MRCPCH (ordinary members)
- Designation FRCPCH (fellows)

\section{Subscriptions (inclusive of Archives) \\ Junior $\quad £ 140.00$ \\ Ordinary $£ 325.00$ \\ Fellow $\quad £ 380.00$ \\ Associate $\quad £ 238.00$}

Concessionary subscriptions are available for those working part time or resident overseas.

Application forms and information on eligibility are available via www.rcpch.ac.uk or by contacting The Membership Section, Royal College of Paediatrics and Child Health, 50 Hallam Street, London WIW 6DE; tel (020) 7307 5619/20/23; fax (020) 7307 5601; email: membership@rcpch.ac.uk. 